J. Asiat. Soc. Bangladesh, Sci. 39(1): 105-115, June 2013

\title{
HISTOPATHOLOGICAL EFFECTS OF EXTRACTS OF TWO INDIGENOUS PLANTS, PONGAMIA PINNATA (L.) PIERRE AND CLERODENDRUM VISCOSUM (VENT.) ON THE CAT FISH, HETEROPNEUSTES FOSSILIS (BLOCH)
}

\author{
MUNIRA NASIRUDDIN, MOHAMMAD ALI AZADI ${ }^{1}$ \\ AND MAHMUDA SHARMIN NELY \\ Department of Zoology, University of Chittagong, Chittagong 4331, Bangladesh
}

\begin{abstract}
Piscicidal properties of part extracts (seed, leaf and bark) of two indigenous plants, Pongamia pinnata (L.) Pierre and Clerodendrum viscosum (Vent.) were studied on Heteropneustes fossilis (Bloch). A number of histopathological lesions was observed in the tissues of intestine, gill and liver of the fish which were treated with $50 \%$ ethyl alcohol extract of the two plant parts toxicants. The principal degenerative changes in the intestine were: disintegrated serosa, swollen and partially ruptured muscularis layer, vacuolated submucosa, damaged mucosa and distended and coalesced villi. The principal changes in the gills included vacuolated and disrupted epithelial cells and disorganized gill filaments, shrunken and oedamatous distensions in the primary lamellae, swollen, shortened and coalesced secondary lamellae and distorted and disintegrated gill arches. The changes in the liver included compactly or loosely arranged hepatic cells, reduced or swollen hepatic artery, disintegrated hepatic vein, blood coagulated portal vein, dilated and swollen central vein and dispersed sinusoids. The most toxic extract for P. pinnata was the leaf extract and for $C$. viscosum was the seed extract in three organs. Among the extracts of three plant parts (seed, leaf and bark) $P$. pinnata was found to be more toxic than C. viscosum.
\end{abstract}

Key words: Histopathology, Plant toxin, Heteropneustes fossilis, Pongamia pinnata, Clerodendrum viscosum

\section{Introduction}

To investigate the impact of toxicants on the ecosystem, it is necessary to study the histopathological effects of toxicants on fish organs. Histological examinations which show pathological alterations upon exposure to toxicants have been useful to assess disease problems (Chen and Kumlin 1989), nutritional stress (Kapoor et al. 1975 and Williams and Nickol 1989), environmental stress (Srivastava et al. 1982) as well as physiological adaptations to salinity changes (Cataldi et al. 1987). The fresh water fishes show dissimilar pattern of responses when exposed to toxicants (Mount 1968 and Gardner and Laroche 1973). The extent of damage varies with body parts, nature of the toxicants, medium and duration of exposure (Vijayamadhawan and Iwai 1975). To

\footnotetext{
${ }^{1}$ Corresponding author: Email: maazadi@yahoo.com
} 
understand the impact of toxicants in aquatic ecosystems, it is necessary to study the histopathological effects of poisons on different fish organs. By histopathological studies we can observe the abnormalities in the tissue structure.

Some information is available on the histopathological effects of plant piscicidal compounds on fish organs. Changes in the tissues as a result of induced toxins i.e., plant piscicides involve only a few reports (Bhatt 1991, 1992, Fafioye et al. 2004, Obomanu et al. 2007, Verma et al. 2007 and Olaifa et al. 2008). In Bangladesh, research work on histopathological effect of plant toxicants in various organs of fishes is limited excepting those of Latifa et al. (2002), Latifa and Begum (2009) and Nasiruddin et al. (2005, 2007, 2008, 2009, 2011).

The present study evaluated the efficacy of the extracts of the two experimental plant parts on the histopathological alterations of the organs- intestine, gill and liver of the test fish, H.fossilis, the effects being induced by $50 \%$ ethyl alcohol extracts of seed, leaf and bark of $P$. pinnata (Karenja) and C. viscosum (Vat) plants. The objective of the study was to see the toxic impact of the dry seed, leaf and bark extracts of the two experimental plants on the histopathological changes of intestine, gill and liver of the fish.

\section{Materials and Methods}

During the investigation, the predatory fish, $H$. fossilis was used to ascertain the histopathological changes so as to determine the toxic effects of $P$. pinnata and $C$. viscosum plant part extracts (seed, leaf and bark). In order to extract the toxicants, seed, leaf and bark of $P$. pinnata and $C$. viscosum were well dried in diffused sun heat and preserved in airtight jars. The plant parts were pounded using metallic mortar and pestle, then crushed into fine powder with an electric grinder and sieved through $0.0025 \mathrm{~cm}^{2}$ mesh size sieve. Required amount of plant part powder was weighed in an electronic pan balance to mix with $50 \%$ ethyl alcohol solvents. The desired concentrations of different test solutions were obtained by appropriate dilution of the stock solution (APHA 1976).

The histopathological effects of dry plant part extracts were observed for 24 hours exposure, the tissues were taken from the fishes that were treated with the second highest concentrations of $50 \%$ ethyl alcohol extract. The histopathological effects of $P$. pinnata on the tissues were observed from the fishes that were treated with $500 \mathrm{ppm}, 1250 \mathrm{ppm}$ and 600 ppm of dry seed, leaf and bark extracts respectively. In case of $C$. viscosum the doses were 300 ppm, $750 \mathrm{ppm}$ and 1000 ppm of dry seed, leaf and bark extracts respectively. A controlled set was similarly maintained in tap water which was free of any kind of extract. Pieces of tissues of intestine, gill and liver were collected from both control and experimental fishes and kept in saline water and fixed in Bouin's fluid overnight. After 18-20 hours, tissues were preserved in 70\% ethyl alcohol. Dehydration was done in progressively graded alcoholic series and embedded in melted paraffin wax. The embedded tissues were trimmed and placed into rotary microtome to get transverse 
and longitudinal sections of the tissues at 3-4 $\mu$ thickness. Dewaxing, hydration and staining with haematoxylin and eosin (aqueous) of the sections were carried out and finally mounted with DPX and cover slip.

The prepared tissues were studied with a compound microscope (x10). The photomicrographs of desired stained histopathological sections were taken with an Axiovert 25 CFL (Germany) microscope fitted with a SLR Canon camera (Japan). Fuji colour films were used for taking the photographs. Microphotographs of desired areas of the sections were taken at magnification factors using eyepiece $10 \mathrm{x}$ and objective $10 \mathrm{x}$.

\section{Results and Discussion}

Histology of intestine of control H. fossilis: The transverse section of intestine of control $H$. fossilis showed the four basic layers: serosa, muscularis, submucosa and mucosa. Serosa was the outer layer of the intestine. It was very thin and made up of single layer of peritoneal cells. Cognominal muscle fibre and circular muscle fibre made the muscularis mucosa. Longitudinal muscle fibre was the thin layer. It was the outer layer of muscularis mucosa. Circular muscle fibre was the thick layer. It was the inner layer of muscularis mucosa. The submucosa consisted of loose connective tissue fibre and simple fold or villi and was made up of single layer of columnar epithelium, which was formed of absorptive and goblet cells. Villi consisted of absorptive and muscle secreting cells (Plate 1A).

Histopathological changes in the intestine of $H$. fossilis treated with $50 \%$ ethyl alcohol extracts of dry seed, leaf and bark of P. pinnata: Treatment with dry seed extract, in the treated intestine serosa was more or less intact but partially damaged; muscularis was swollen to an extent; submucosa was organized but vacuolated and swollen; lamina propria was normal; mucosa was fused, disorganized, disintegrated and coalesced; and villi were slightly swollen and fused with each other, irregular and extensively damaged (Plate 1B). Treatment with dry leaf extract, the serosa was not intact but partially damaged; muscularis was organized and swollen to an extent; submucosa was proliferated and disintegrated very much; lamina propria was reduced; mucosa was disorganized and disintegrated very much; and villi were disorganized, disintegrated, proliferated, elongated and ruptured (Plate 1C). With dry bark extract treatment, serosa was more or less intact but disintegrating in some portion; muscularis was not so organized and slightly swollen and proliferated in some places; submucosa was not organized but proliferated; lamina propria was disintegrated; mucosa was compact, swollen, proliferated and coalesced; and villi were elongated, swollen and also fused with each other (Plate 1D).

Histopathological changes in the intestine of $\mathrm{H}$. fossilis treated with dry seed, leaf and bark extracts of C. viscosum: Treatment with dry seed extract, serosa was more or less intact; muscularis was organized but swollen; submucosa was slightly proliferated but swollen; lamina propria was not organized but swollen; mucosa was shrunken, swollen, 

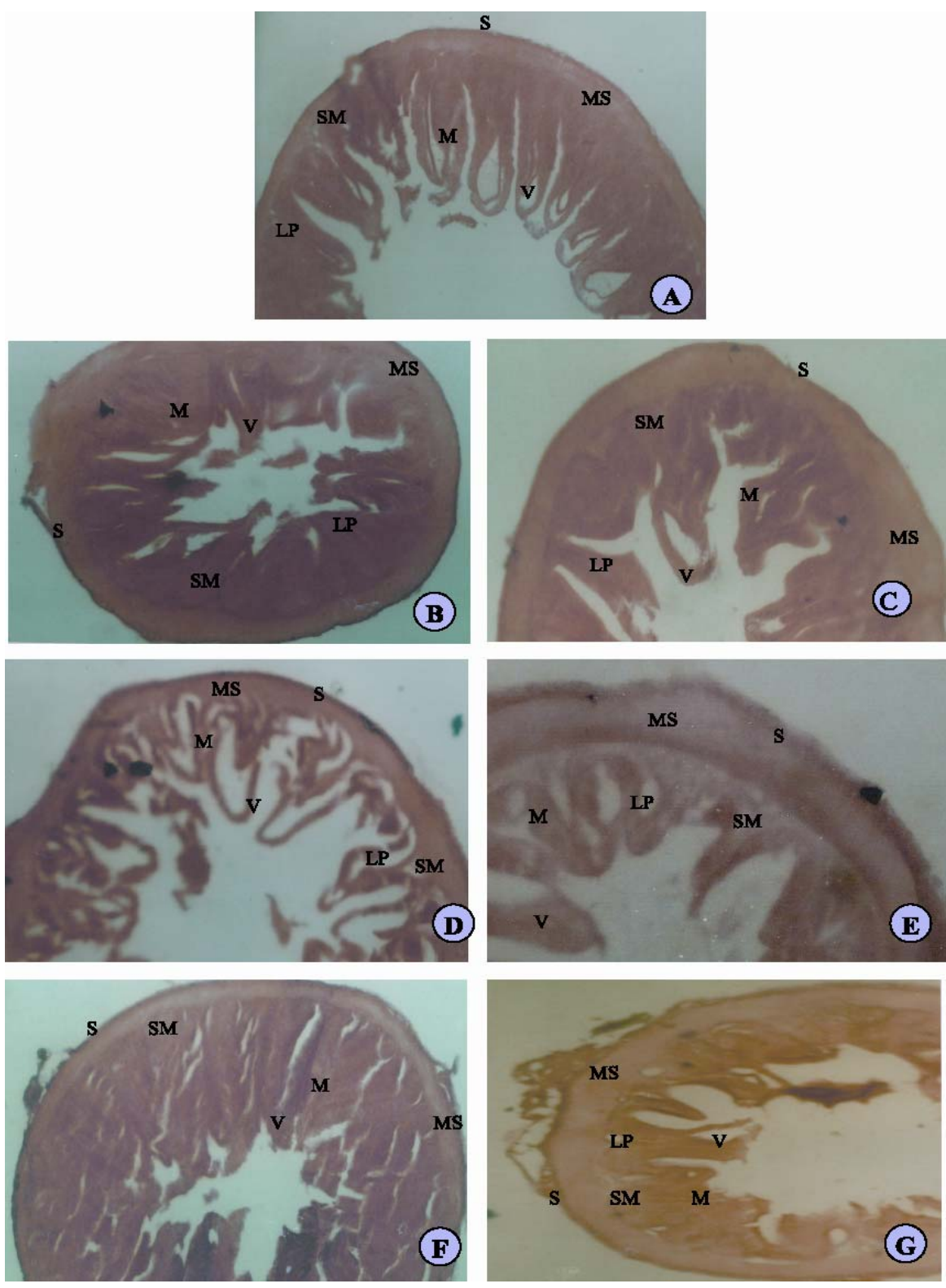

Plate 1. (a) Photomicrographs of the T. S. of the intestine of the H.fossilis in control, (b) Treated with dry seed, (c) Dry leaf and (d) Dry bark of P. Pinnata and (e) Treated with dry seed, (f) Dry leaf and (g) Dry bark of C. viscosum (S- serosa, Ms- Muscularis, Sm- submucosa, M- mucosa, Lp- lamina Propria and V-villi) (x100). 
deshaped, irregular and coalesced; and villi were extensively swollen, fused in some places and damaged (Plate 1E). Being treated with dry leaf extract, serosa was more or less intact but proliferated in some portion; muscularis was swollen to an extent; submucosa was slightly extended; lamina propria was normal; mucosa was disorganized and fused in some portion; and villi were compact, slightly swollen and elongated (Plate 1F). After treatment with dry bark extract, serosa was not intact but partially damaged; muscularis was swollen to an extent; submucosa was normal to slightly proliferated; lamina propria was swollen; mucosa was disorganized, swollen and coalesced, some were shrunken and damaged; and villi were disintegrating, shortened, swollen, also fused with each other and damaged (Plate $1 G)$.

Histology of gill of control H. fossilis: The control gill had normal morphology of the hyaline cartilaginous rods in each filament. Four pairs of reddish gill filaments and leaf like primary gill lamellae were found in $H$. fossilis. Primary gill lamellae consisted of secondary gill lamellae. Primary lamellae were borne by gill arches. Single large squamous epithelial cells and numerous mucus cells lay scattered on both sides of the epithelial cells of the normal gill lamellae. The gill lamellae were semicircular, attached basally and partially, overlapped one another on either side of the filament. They were supported by gill rays, which were partly bony and were connected with gill arch and with each other by fibrous ligaments. For gaseous exchange the surface of each gill filament was thrown into numerous small folds, which increased the sum total surface area of the gills (Plate 2A).

Histopathological changes in the gill of $\mathrm{H}$. fossilis treated with dry seed, leaf and bark extracts of P. pinnata: After treatment with dry seed extract, gill filaments were more or less organized; primary gill lamellae were more or less swollen; secondary gill lamellae were swollen, coalesced and destroyed in some regions; gill rays were highly swollen and damaged in some regions; and gill arch was proliferated and distorted with vacuolations (Plate 2B). After treating with dry leaf extract, the gill filaments were more or less organized; primary gill lamellae were more or less swollen; secondary gill lamellae were slightly swollen and coalesced in some regions; gill rays were swollen and damaged; and gill arch was quite normal and organized (Plate 2C). With dry bark extract treatment, gill filaments were not well organized; primary gill lamellae were swollen and moderately shrunken; secondary gill lamellae were coalesced and swollen at the base, atrophied and shrunken at the apex; gill rays were swollen and damaged extensively; and gill arch was damaged and disorganized to some extent (Plate 2D).

Histopathological changes in the gill of $H$. fossilis treated with dry seed, leaf and bark extracts of $C$. viscosum: When the fishes were exposed to dry seed extract, gill filaments were swollen, distended and disorganized; primary gill lamellae were swollen and disorganized; secondary gill lamellae were swollen and extended at the base and atrophied and shrunken at the apex; gill rays were damaged at the base and swollen at the 

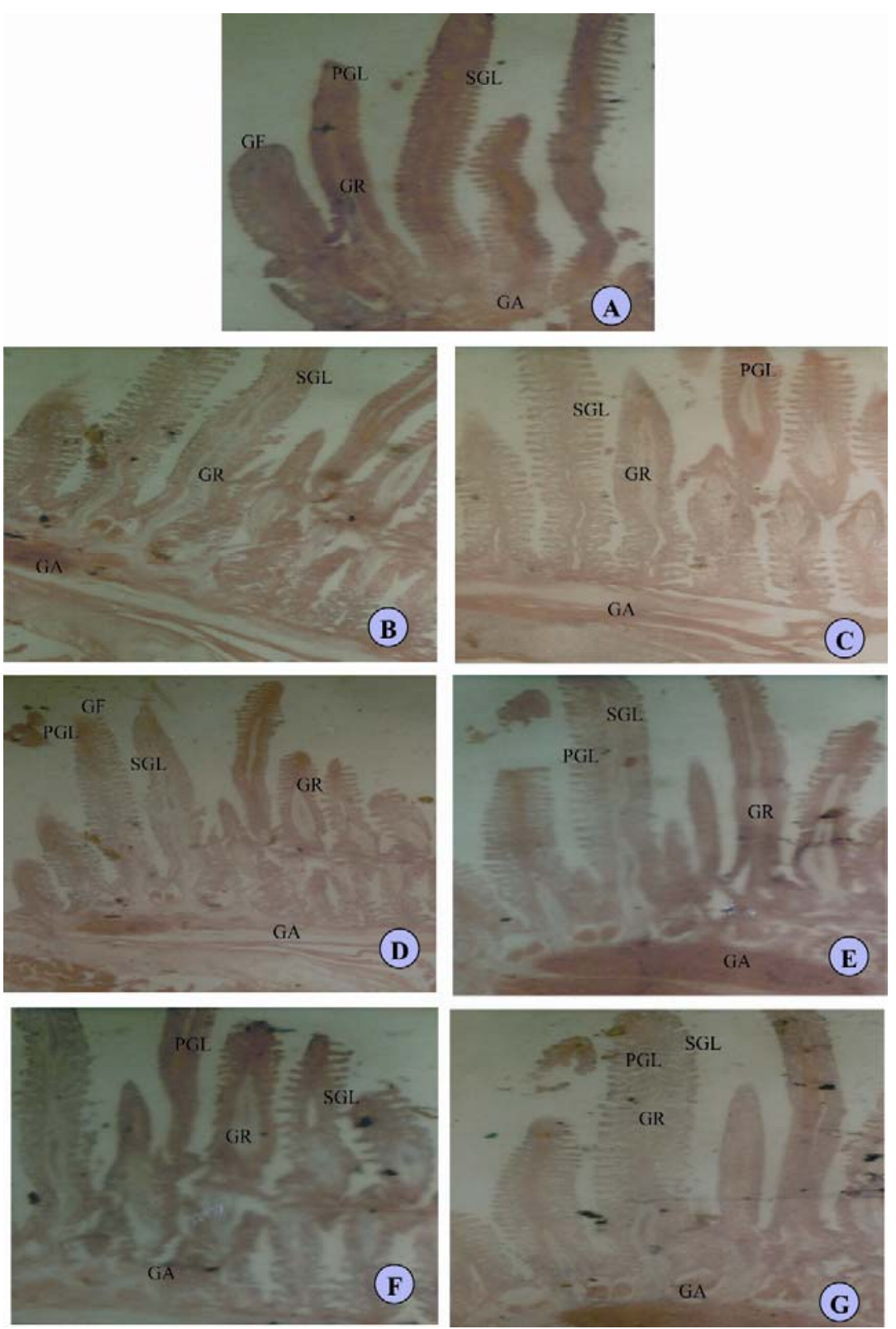

Plate 2. (a) Photomicrographs of the T. S. of the gill of the H.fossilis in control, (b) treated with dry seed, (c) dry leaf and (d) dry bark of P.pinnata and (e) treated with dry seed, (f) dry leaf and (g) dry bark of $C$. viscosum (Gf- gill filaments, pgl- primary gill lamellae, sgl- secondary gill lamellae, gr- gill ray and gagill arch) (x100). 
tip; and gill arch was more or less organized (Plate 2E). After treatment with dry leaf extract, gill filaments were disorganized and damaged; primary gill lamellae were extensively swollen and distended; secondary gill lamellae were coalesced and swollen and also destroyed in some areas; gill rays were highly swollen; and gill arch was proliferated, distorted and vacuolated (Plate 2F).With dry bark extract, gill filaments were more or less organized; primary gill lamellae were swollen in some regions; secondary gill lamellae were swollen and coalesced; gill rays were highly swollen in some places; and gill arch was more or less organized (Plate 2G).

Histology of liver of control H. fossilis: Control liver had normal arrangement with components of numerous polyhedral hepatic cells with a prominent nuclei and granular cytoplasm. This structure indicated their secretory nature. But these cells had no definite arrangement. Hepatic cells radiated outwards from the central vein and constituted the parenchyma. Blood sinusoids separated the parenchymatous cells. There were no definite cell cords and no hepatic lobules. Portal vein, hepatic artery, hepatic vein, central vein and bile duct spread throughout the liver. Hepatic ducts and ductules and blood capillaries were seen between the spaces of hepatic cells (Plate 3A).

Histopathological changes in the liver of $\mathrm{H}$. fossilis treated with dry seed, leaf and bark extracts of P. pinnata: Upon exposure to dry seed extract, hepatic cells were compact and condensed; hepatic artery was elongated and disintegrated; hepatic vein was dilated with clotted blood; portal vein was much distended; central vein was with clotted blood; blood vessels were reduced and shrunken; and blood sinusoids were not clear (Plate 3B). Treatment with dry leaf extract, the hepatic cells were swollen, vacuolated and disintegrated; hepatic artery was deshaped, disintegrated and narrowed in size; hepatic vein was deshaped, disintegrated and with coagulated blood; wall of portal vein was destroyed, disintegrated, deshaped and with coagulated blood; central vein was dilated with clotted blood; blood vessels were shrunken and disintegrated; and blood sinusoids were irregularly distributed (Plate 3C). Treatment with dry bark extract, the hepatic cells were swollen and pyknotic with vacuolation of the cytoplasm; hepatic artery was shrunken with coagulated blood; wall of hepatic vein was destroyed; portal vein was dilated with clotted blood; central vein was normal in size; blood vessels were normal; and spaces of blood sinusoids did not fill the cavities suggesting decreased blood supply (Plate 3D).

Histopathological changes in the liver of $\mathrm{H}$. fossilis treated with dry seed, leaf and bark extracts of C. viscosum: When the fishes were exposed to dry seed extract, the hepatic cells were more or less organized, much swollen and pyknotic, some were also vacuolated; hepatic artery was elongated in shape and slightly distended; hepatic vein was with coagulated blood; portal vein was deshaped and disintegrated; blood vessels were normal but some with coagulated blood; and blood sinusoids were irregularly distributed (Plate 3E). Duetotreatment with dry leaf extract, the hepatic cells were swollen 

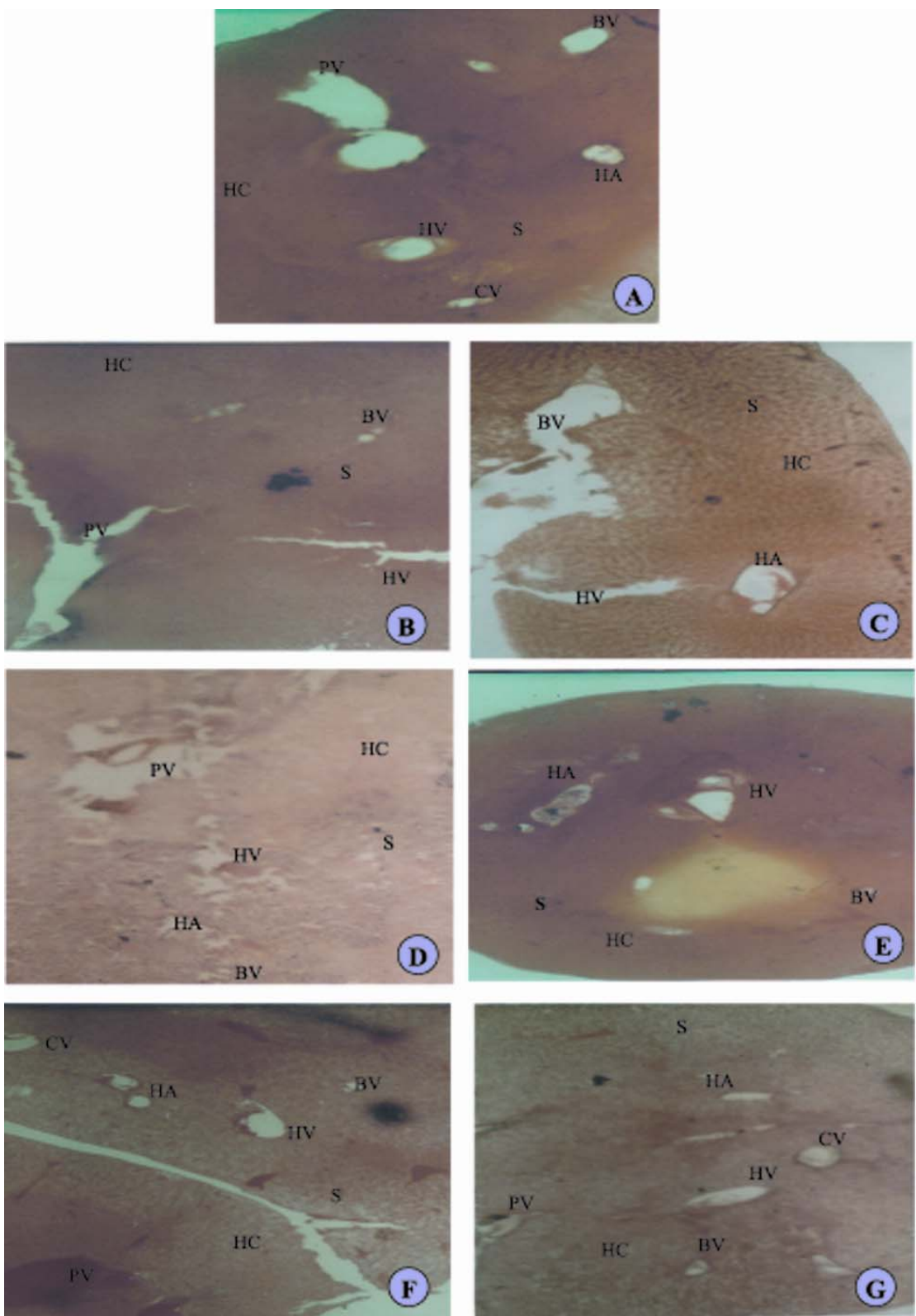

Plate 3. (a) Photomicrographs of the T. S. of the liver of the H.fossilis in control, (b) treated with dry seed, (c) dry leaf and (d) dry bark of p.pinnata and (e) treated with dry seed, (f) dry leaf and (g) dry bark of C.viscosum (hc- hepatic cells, ha- hepatic artery, hv- hepatic vein, pv- portal vein, cv- central veins, s- blood sinusoids and bv- blood vessels) (x100). 
and compact; hepatic artery was reduced and distorted in shape and with coagulated blood; hepatic vein was deshaped and disorganized; portal vein was slightly distended with clotted blood; central vein was reduced in size but with clotted blood; blood vessels were shrunken; and blood sinusoids were not organized (Plate 3F). Treatment with dry bark extract, the hepatic cells were very much swollen and pyknotic, some were also vacuolated; hepatic artery was reduced in size and elongated; hepatic vein was reduced with coagulated blood; portal vein was elongated and with coagulated blood; central vein was shrunken with clotted blood; blood vessels were reduced; and blood sinusoids were regularly distributed (Plate $3 \mathrm{G})$.

The histopathological changes in the intestine, gill and liver of $H$. fossilis of the present observation showed similarities with the findings of Nasiruddin et al. (2008, 2009 and 2011), when the test fishes were treated with Acacia auriculaeformis, Mesua ferrea, Madhuca indica and Tabarnaemontana divaricata plant part extracts (seed, leaf and bark). In the present experiments, it was observed that the most affected organs were the gill and intestine and then liver. Necrosis of the intestinal wall might have interfered with the normal function of digestion and absorption. Malfunctioning of intestine might result in total disorder in the digestive system leading to starvation. Gill is one of the most susceptible organs affecting the respiratory and osmoregulatory ability of the fish. It might be said that the increased acute toxicity of the toxicant lead to hyperventilation in fishes which was due to contact of gill surface to the increased amount of toxicant in the water. Furthermore, histopathological changes in the gill structure could impair respiratory function by reducing the surface area for gaseous exchange. Finally, gill alterations are related to gill function disorders, which might affect the physiology or cause death of fish (Smart 1976). It is also inferred that lesion in the gill morphology could lead to functional alteration and interference with fundamental processes such as osmoregulation and gaseous exchange in the toxicant exposed fishes. Liver is the major organ of detoxification. The histopathological changes also lead to a reduction of functional efficiency of the liver, leading to malfunctioning. These disorders in the affected organs cause malfunctioning of the organs as well as the systems resulting in physiological disturbance which in turn might cause death of the fish.

A comparative study of these two plant part extracts on the basis of histopathology was made on H. fossilis. While observing the histopathological effects it was seen that the effect of P. pinnata leaf extracts showed greatest affectivity followed by seed and bark extracts, whilst the effect of C. viscosum seed extracts showed greatest affectivity followed by bark and leaf extracts.

In the present investigation, on the basis of histopathology, the trends of toxicity of the three plant part extracts of $P$. pinnata on the three studied organs were: in the intestine effects of leaf $>$ seed $>$ bark extracts; in the gill - effect of leaf $>$ seed $>$ bark extracts; and in the liver - effect of leaf $>$ bark $>$ seed extracts. Thus, on comparison, it is seen that the leaf extract was the most effective on the three organs, than seed extract followed by 
bark extract. In case of $C$. viscosum the trends of toxicity on the basis of histopathology of the three plant part extracts on the three studied organs were: in the intestine - effect of seed $>$ bark > leaf extracts; in the gill - effect of seed $>$ bark $>$ leaf extracts; and in the liver - effect of seed $>$ leaf $>$ bark extracts. Thus, on comparison, it is seen that the seed extract was the most effective on the three organs followed by bark and leaf extracts.

The observed altered histological changes were as a result of various pathological or toxicological factors. The active ingredients of the plant parts of $P$. pinnata and $C$. viscosum caused histopathological necrosis in the intestine, gill and liver of $H$. fossilis and influenced the physiological activities of the fish resulting in death.

\section{References}

APHA 1976. Standard methods for the examination of water and waste water. APHA press, Washington DC. 1193 pp.

Bhatt, J.P. 1991. Neurolytic manifestation of piscicidal flavanoid of plant Engelhardtia colebrookiana (Lindle) in fish. Indian. J. Exp. Biol. 29: 588-590.

Bhatt, J.P. 1992. Neurodepressive action of a piscicidal glycoside of plant, Aesculus indica (Colebr.) in fish. Indian. J. Exp. Biol. 30: 437-439.

Cataldi, E., S. Cataudella, G. Monaco, A. Rossi and L. Tancioni. 1987. A study of the histology and morphology of the digestive tract of the sea bream Sparus aurata. J. Fish Biol. 30(2): $135-145$.

Chen, M.F. and M.E. Kumlin. 1989. Enteric septicemia of channel catfish in California. California fish and Game. 75: 141-147.

Fafioye, O.O., A.A. Adebisi and S.O. Fagade. 2004. Toxicity of Parkia biglobosa and Raphia vinifera on Clarias gariepinus juveniles. Afr. J. Biotechnol. 3(11): 627-630.

Gardner, G.R. and G. Laroche. 1973. Copper induced lesions in estuarine teleosts. J. Fish. Res. Bd. Canada. 30: 363-368.

Kapoor, B.G., H. Smith and I.A. Verighina. 1975. The alimentary canal and digestion in teleosts. Adm. Mar. Biol. 13: 109-239.

Latifa, G.A. and T. Begum. 2009. Histopathological effects of Leucaena leucocephala (Lam. De Wit) seed oil on Channa punctatus (Bloch). Bangladesh J. Zool. 37(2): 201-211.

Latifa, G.A., A. Hamid and G. Sharma. 2002. Study of piscicidal activity of dry bark of Diospyros ebenun (Koen) on Heteropneustes fossilis (Bloch) and Anabas testudineus (Bloch). Bangladesh J. Life. Sc. 14(1 and 2): 107-118.

Mount, D.E. 1968. Chronic toxicity of copper to the fathead minnows (Pimephales promelas). Water Res. 2: 215-223.

Nasiruddin, M., M.A. Azadi and F. Tabassum. 2005. Histopathological effects of Cassia siamea (Linn.) and Datura metel (Linn.) seed extracts on Heteropneustes fossilis (Bloch) and Channa punctatus (Bloch). Bangaladesh J. Zool. 33(1): 17-26.

Nasiruddin, M., M.A. Azadi and N. Sultana. 2007. Histopathological effects of dry seed extracts of four medicinal plants on Hetertopneustes fossilis (Bloch). The Chittagong Univ. J. B. Sci. 2(1 and 2): 113-126.

Nasiruddin, M., M.A. Azadi and I.A.S. Rahman. 2008. Histopathological changes in the gill, liver and intestine of Heteropneustes fossilis (Bloch) treated with Acacia auriculaeformis (A. Cunn. Ex. Benth). and Mesua ferrea (Linn.) plant parts. Bangaladesh J. Zool. 36(2): 155166.

Nasiruddin, M., M.A. Azadi and Ashrafunnessa. 2009. Histopathological changes in the gill, liver and intestine of Heteropneustes fossilis (Bloch) treated with extracts of different parts of Madhuca indica (G.F. Gmel). The Chittagong Univ. J. B. Sci. 4(1 and 2): 119-130. 
Nasiruddin, M., M.A. Azadi, A. Hossain and S.I. Ara. 2011. Histopathological alterations in the gill, liver and intestine of Heteropneustes fossilis (Bloch) treated with Tabarnaemontana divaricata (L.) plant part extracts. Bangladesh J. Zool. 39(1): 99-109.

Obomanu, F.G., O.K. Ogbalu, U.U. Gabriel, S.G.K. Fekarurhobo and S.U. Abadi. 2007. Piscicidal effects of Lepidagathis alopecuroides on mudskipper, Periophthalmus papilio from the Niger delta. Research Journal of Applied Sciences. 2(4): 382-387.

Olaifa, F.E., R.A. Hamzat and O.O. Oyetoyan. 2008. Acute toxicity of ethanol extracts of cocoa bean shell on Sarotherdon galilaeus juveniles. Journal of Fisheries International 3(3): 56-60.

Smart, E. 1976. The effects of ammonia exposed on the gill structure of the rainbow trout (Salmo gairdneri). J. Fish Res. Board Canada: 328-329.

Srivastava, V.M.S., R.S. Tripathi and A.K. Saxena. 1982. Chromium induced histopathological changes in fishes of Puntius sophore (Hamilton). J. Biol. Res. 2: 67-68.

Verma, P., D.K. Kedia and A. Nath. 2007. Protective effect of Ocimum sanctum leaf extracts against rogor induced ovarian toxicity in Clarias batrachus (Linnn). J. Ecophysiol. Occup. Hlth. 7: 177-184.

Vijayamadhawan, K. T. and T. Iwai. 1975. Histochemical observations on the permeation of heavy metals into taste buds of goldfish. Bull. Dap. Soc. Sci. Fish. 41: 631-639.

Williams, J.A. and B.B. Nickol. 1989. Histological structure of the intestine and pyloric caeca of the green sunfish, Lepomis cyanellus Rafinesque. J. Fish. Biol. 35: 359-372. 